\title{
Assessment of Internship Nursing Students' Performance toward Infection Control Precautions regarding Intravenous Infusion
}

\author{
Soad Ali Jomaan ${ }^{1}$, Esmat Sayed Abd El-mageed ${ }^{2}$, Marwa Ali Almasry ${ }^{3}$. \\ ${ }^{1 .}$ Instructor of Medical Surgical Faculty of Nursing, Hadhramout University, Yemen. \\ 2. Assistant Professor of Medical Surgical Nursing Faculty of Nursing, Assiut University, Egypt. \\ ${ }^{3 .}$ Lecturer of Medical Surgical Nursing Faculty of Nursing, Assiut University, Egypt.
}

\begin{abstract}
Background: Internship nursing students are often exposed to various infections during their clinical education. Knowledge and compliance with infection control precautions are essential to prevent hospital associated infections and protect patients as well as medical workers from exposure to infectious agents. The aim of this study was to assess internship nursing students' knowledge and practice toward infection control precautions regarding intravenous infusion. Subject: All available internship nursing students who graduated in 2019 from Faculty of Nursing, Assiut University, during their training period within 4 months. Setting: The study was conducted in ElRajhi Liver Hospital, Neurological and Psychiatric Hospital and El- Orman Heart Hospital at Assiut University Hospitals and in South Egypt Cancer Institute. Two tools were utilized for data collection; structured questionnaire and observational checklist for internship nursing students toward infection control precautions regarding IV infusion. Results: 250 internship nursing students participated in this study, most of them (86\%) attended training program about infection control. This study revealed that the internship nursing students had good knowledge and adequate practice $(100 \%$ and $66.8 \%)$ respectively toward infection control precautions regarding IV infusion. Conclusions: Internship nursing students under study had good level of knowledge and adequate practice about infection control precautions regarding IV infusion. Recommendations: The periodic refreshing in-service training courses should be provided to internship nursing students in order to keep them with updated knowledge and practice about infection control precautions regarding IV infusion.
\end{abstract}

\section{Keywords: Internship Students, Nursing Performance, Infection Control Precautions \& IV Infusion.}

\section{Introduction}

Intravenous (IV) infusion is the administration of substances directly into the patient's vein for therapy in order to maintain or restore fluid and electrolyte balance when there is inadequacy or impossibility of oral replacement. This includes fluid infusion, blood transfusion, administration of medication, and nutritional support. However, when the integrity of the skin is compromised by usage of any venous access such as needle and cannula, the patients will be at risk for infection (Khairunniza et al., 2019).

More than a billion peripheral IV catheters are inserted for hospitalized patients worldwide each year. In the United States, approximately 300 million peripheral IV catheters are inserted into adult patients. It is estimated that more than half $(59 \%$ to $70 \%)$ of admitted patients require a peripheral IV line during their hospital stay. The incidence of bloodstream infection is about 0.18 percent (i.e., close to two such infections for every 1,000 of these catheters inserted), IV infusion is believed to account for one third of all nosocomial bacteremia (Mermel, 2017 \& Etafa et al., 2020).
Infection continues to be a major problem associated with IV infusion. Infection may be localized or systemic; however, peripheral IV cannulations are more commonly associated with localized than systemic infection and they are associated with increased risk of bacteremia, which can prolong length of hospital stay and increase health care costs (Blauw et al., 2019).

Infection prevention and control refers to evidencebased practices and procedures that, when applied consistently in health care settings can prevent or minimize the risk of transmission of microorganisms to health care providers, patients, residents and visitors (Beyamo et al., 2019).

Nursing students can be exposed to serious health care-associated infections, if they are not following infection prevention and control measures. Knowledge and compliance with standard precautions are essential to prevent hospital associated infections and protect patients as well as medical workers from exposure to infectious agents (Anabtawi et al., 2019). 
The Centers for Disease Control and Prevention (CDC) in 2017 offered a sequence of precautions during IV infusion. It includes performing hand hygiene before and after inserting, replacing or dressing an IV catheter, wearing clean gloves and maintaining aseptic technique for the insertion of IV catheters, preparing skin with an antiseptic (70\% alcohol, iodine, or 2\% chlorhexidine) before insertion, using sterile, transparent, semipermeable dressing to cover the IV catheter and replacing it if becomes damp, loosened, or soiled. Injection ports and diaphragms of multi dose vials should be cleansed with $70 \%$ alcohol prior to accessing, IV catheter, IV administration sets and extensions should be replaced every 72 hours, unless infection is suspected or documented.

\section{Significance of the study}

It has been reported in several epidemiological studies that healthcare workers such as physicians, dentists and nurses are implicated in the transmission of nosocomial infections. Literature that has explored the knowledge and practices of nurses is limited (Fashafsheh et al., 2015).

The internship nursing students are in high risk for exposure to various infections during their clinical education. Knowledge and practices with infection control precautions are essential (Labrague et al., 2012). So this study will be conducted to assess the internship nursing students' performance toward infection control precautions regarding IV infusion.

Aim of the study

The aim of the study is to assess internship nursing students' knowledge and practice toward infection control precautions regarding IV infusion.

\section{Research question}

What are the internship nursing students' knowledge and practice toward infection control precautions regarding IV infusion?

\section{Subjects \& Methods \\ Research design}

A cross-sectional descriptive research design was utilized in this study.

\section{Setting:}

The study was conducted in El- Rajhi Liver Hospital, Neurological and Psychiatric Hospital and El- Orman Heart Hospital at Assiut University Hospitals and in South Egypt Cancer Institute. These selected hospitals where the students were attending their training period.

\section{Sample}

All available internship nursing students who graduated in 2019 from Faculty of Nursing, Assiut University, during their training period within 4 months. They were 250 students distributed as following: (60 students in El- Rajhi Liver Hospital, 60 students in Neurological and Psychiatric Hospital, 60 students in El- Orman Heart Hospital and 70 students in South Egypt Cancer Institute).

\section{Tools of data collection}

Two tools were utilized to collect data of the present study.

Tool I -Structured questionnaire:

It was developed by the researcher to assess the knowledge level of the internship nursing students about infection control precautions regarding IV infusion, the questionnaire consisted of two parts;

Part 1: Personal data of internship nursing students:

It was developed to assess the personal data such as; age, sex, marital status, residence and attending previous training about infection control precautions.

Part 2: Knowledge about infection control precautions regarding IV Infusion

It was developed to assess students' knowledge about infection control precautions regarding IV infusion such as, infection control, hand hygiene, wearing gloves, handling sharp instrument, environmental hygiene, caring of catheter dressing and giving IV infusion.

Scoring system

The total number of questions were 20, one grade awarded for the correct answer and zero for the incorrect one .

The total knowledge score was determined as follow:

$$
\begin{array}{lll}
\text { - } & \text { Poor } & <50 \% \\
\text { - } & \text { Fair } & 50 \%-<70 \% \\
\text { - } & \text { Good } & \geqslant 70 \%
\end{array}
$$

Tool II -Observation checklist for internship nursing students about infection control precautions regarding IV infusion

It was developed by the researcher after reviewing the relevant literatures to assess internship nursing students' practices toward infection control precautions regarding IV infusion. It included pre, during and post the procedure as following initiating a peripheral IV infusion (13 items), caring and maintenance of IV catheter (7 items), discontinuing an IV infusion (9 items) and environmental hygiene (6 items). It was used during students' routine work in hospitals.

Scoring system

Each item in checklist was scored as follow: One grades for each step that done correct and zero for step that not done. $<70 \%$ were graded as inadequate level of practice and $\geqslant 70 \%$ was graded as adequate level of practice.

Methods

Content validity

The face validity was done by five experts from Medical Surgical Nursing staff who reviewed the 
study tools for clarity, relevance, comprehensiveness, applicability and easiness. The reliability was carried out using the Cronbach alpha test to internship nursing students' knowledge questionnaire of infection control precautions regarding IV infusion, and observational checklist for assessment of internship nursing students' practices toward infection control precaution regarding IV infusion. It was found to be $(r=0.92 \& 0.84)$ respectively.

\section{Pilot study}

The pilot study carried out in January 2020 to test the feasibility and applicability of the study tools. It was conducted on $10 \%$ of the sample (25 internship nursing students) to estimate the time needed to fill out the tools. The data obtained from the pilot study were analyzed and no changes were done, so the sample of the pilot study was included in the main study.

\section{Procedure}

- An official approval letter was obtained from the dean of the Faculty of Nursing.

- An official approval for data collection was obtained from administrators of the selected hospitals.

- Data were collected from the selected hospitals in the morning and afternoon shifts.

- At initial interview the researcher introduced herself to initiate a line of communication.

- Internship nursing students' agreement for voluntary participation was obtained and purpose and nature of the study was explained.

- The researcher obtained the personal data from the internship nursing students using tool I- part (1).

- Assessment of the internship nursing students' knowledge about infection control precautions during IV infusion using tool I-part (2). The tool was filled by internship nursing students through interviewing.

- Assessment of the internship nursing students using observation checklist (Tool II) which filled by the researcher. Observational checklist was carried out while the internship nursing students were on duty during morning and afternoon shifts. The students were observed by researcher while they performing infection control precautions regarding IV infusion for their patients by using direct observational technique.

- The period of data collection was 4 months from January 2020 to June 2020 with the exception of March and April 2020 because internship nursing students were stopped training in this time because of covid-19 pandemic.

\section{Statistical analysis}

The statistical Package for (SPSS) version (23) was used to analyze data. Descriptive statistics was used for the quantitative data in knowledge, and personal data. Descriptive statistics included frequencies, percentages and means \pm SD. Independent t-test and Pearson correlation were used to find out the relationship between total knowledge, practice and personal data (correlation is significant at the 0.05).

\section{Ethical considerations}

1. Research proposal was approved from Ethical Committee in the Faculty of Nursing.

2. There was no risk for study subjects during application of research.

3. The study followed common ethical principles in clinical research.

4. Oral consent was obtained from internship students that were willing to participate in study, after explaining the nature and purpose the study.

5. Confidentiality and anonymity were assured.

6. Study subjects had the right to refuse to participate and or withdraw from the study without any rational any time.

7. Study subjects privacy was considered during collection of data. 


\section{Results}

Part I. Personal data of internship nursing students.

Table (1): Frequency and percentage distribution of personal data of internship nursing students (n=250).

\begin{tabular}{|l|c|c|}
\hline \multicolumn{1}{|c|}{ Personal data } & N. & \% \\
\hline Age: & & \\
\hline (Mean \pm SD) & $23.3 \pm 1.5$ & \\
\hline Sex: & & 44.0 \\
\hline Male & 110 & 56.0 \\
\hline Female & 140 & \\
\hline Marital status: & 219 & 87.6 \\
\hline Single & 31 & 12.4 \\
\hline Married & & \\
\hline Residence: & 114 & 45.6 \\
\hline Urban & 136 & 54.4 \\
\hline Rural & 215 & \\
\hline Did you attend training program about infection control precautions as a general? & 86.0 \\
\hline Yes & 35 & 14.0 \\
\hline No & & \\
\hline Where did you get this program? & 209 & 83.6 \\
\hline College & 6 & 2.4 \\
\hline Hospital & & \\
\hline How long was this program & 188 & 75.2 \\
\hline 1-3 days & 7 & 2.8 \\
\hline 4-6 days & 20 & 8.0 \\
\hline More 6 days & & \\
\hline
\end{tabular}

Part II. Knowledge about infection control precautions during IV Infusion:

Table (2): Frequency and percentage distribution of studied sample according to their level of knowledge $(n=250)$.

\begin{tabular}{|l|c|c|}
\hline \multicolumn{1}{|c|}{ Level of knowledge } & N. & \% \\
\hline Poor knowledge $<50 \%$ & 0 & 0 \\
\hline Fair knowledge $50 \%-70 \%$ & 0 & 0 \\
\hline Good knowledge $>70 \%$ & 30 & 100.0 \\
\hline Total mean score & \multicolumn{2}{|c|}{$17.98 \pm 1.18$} \\
Minimum & \multicolumn{2}{|c|}{20.00} \\
Maximum & & \\
Total score 20 & & \\
\hline
\end{tabular}

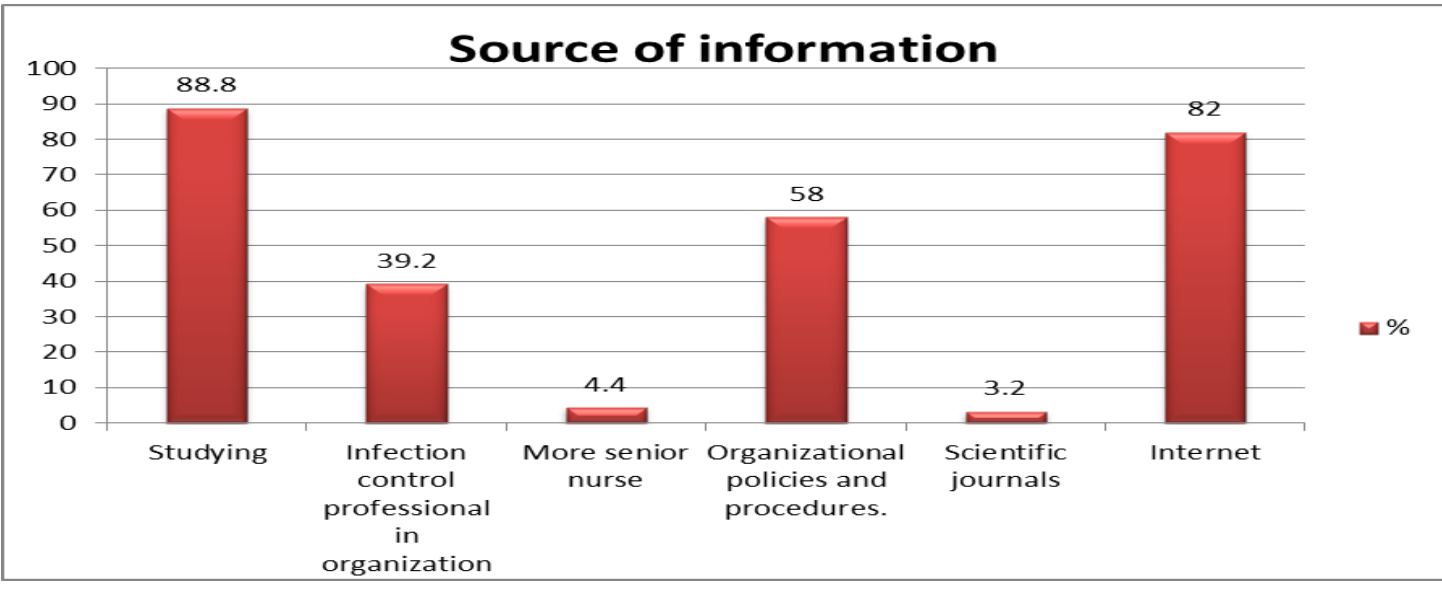

Figure (1): percentage distribution of internship nursing students regarding their sources of information about infection control precautions $(n=250)$. 
Part III. Internship nursing students' practice related to infection control precautions during (IV) infusion: Table (3): Frequency and percentage distribution of observational checklist for internship nursing students

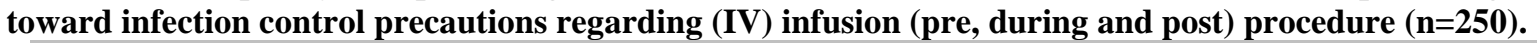

\begin{tabular}{|c|c|c|c|c|}
\hline \multirow{2}{*}{ Procedure } & \multicolumn{2}{|c|}{ Done } & \multicolumn{2}{|c|}{ Not done } \\
\hline & $\mathbf{N}$. & $\%$ & N. & $\%$ \\
\hline Initiating a peripheral IV infusion & 186 & 74.4 & 64 & 25.6 \\
\hline Caring / maintenance of IV catheter & 109 & 43.6 & 141 & 56.4 \\
\hline Discontinuing an IV infusion & 141 & 56.4 & 109 & 43.6 \\
\hline Environmental hygiene & 249 & 99.6 & 1 & 0.4 \\
\hline
\end{tabular}

Table (4): Frequency and percentage distribution of total internship nursing students practice score about infection control precautions regarding (IV) infusion $(n=250)$

\begin{tabular}{|l|c|c|}
\hline \multicolumn{1}{|c|}{ Items total score 35 marks } & N. & \% \\
\hline Adequate $\geq 70 \%$ (above 25marks) & 167 & 66.8 \\
\hline Inadequate $<70$ less 25 marks & 83 & 33.2 \\
\hline
\end{tabular}

Table (5): Relation between, knowledge, practice and personal data of internship nursing students about infection control precautions regarding IV infusion $(n=250)$.

\begin{tabular}{|c|c|c|c|c|}
\hline & & Mean \pm SD & f-test & p.value \\
\hline \multicolumn{5}{|l|}{ - Sex } \\
\hline \multirow[t]{3}{*}{ Knowledge } & Male & $37.44 \pm 1.56$ & \multirow{3}{*}{3.143} & \multirow{3}{*}{ p. $=.077$} \\
\hline & Female & $37.78 \pm 1.45$ & & \\
\hline & Total & $37.63 \pm 1.51$ & & \\
\hline \multirow[t]{3}{*}{ Practice } & Male & $28.20 \pm 3.06$ & \multirow{3}{*}{-3.824} & \multirow{3}{*}{$\mathrm{p} .=.052$} \\
\hline & Female & $27.47 \pm 2.80$ & & \\
\hline & Total & $27.79 \pm 2.94$ & & \\
\hline \multicolumn{5}{|c|}{ - Attending training about infection control } \\
\hline \multirow[t]{2}{*}{ Knowledge } & Yes & $38.20 \pm 1.65$ & \multirow{2}{*}{5.765} & \multirow{2}{*}{ p. $=.017 *$} \\
\hline & No & $37.54 \pm 1.47$ & & \\
\hline \multirow[t]{2}{*}{ Practice } & Yes & $27.02 \pm 3.12$ & \multirow{2}{*}{2.762} & \multirow{2}{*}{ p. $=.098$} \\
\hline & No & $27.91 \pm 2.89$ & & \\
\hline
\end{tabular}

Independent t-test

* statistically significant difference

Table (5): Correlation between knowledge and practice of internship nursing students about infection control precautions regarding IV infusion $(n=250)$.

\begin{tabular}{|l|l|c|}
\hline \multicolumn{2}{|c|}{} & Total practice \\
\hline \multirow{2}{*}{ Total knowledge } & Pearson Correlation & .072 \\
\cline { 2 - 3 } & Sig. (2-tailed) & .256 \\
\hline
\end{tabular}

Correlation is significant at the 0.01 level (2-tailed).*

Table (1): Showed that more than half of the studied samples were females and from rural area, the majority of them $(87 \%)$ were singles and their mean age was $23.3 \pm 1.5$. Regarding attending training program about infection control precautions, the highest percentage of them attended training program in their college during the orientation phase (preparation of internship nursing students before involving them in clinical training in hospitals) in a period between $1-3$ days $(86.0 \%, 83.6 \%$ and $75.2 \%$ respectively).

Table (2): Showed that all the studied subjects had good level of knowledge $(100 \%)$ with total mean score $17.98 \pm 1.18$.

Figure (1): Explained that the sources of information about infection control among the majority of studied sample were the studying and internet $(88.8 \%$ and $82 \%$ ) respectively, while half of them acquired their information from the organizational policies and 
procedures $(58 \%)$ during practical training in the hospitals.

Table (3): Described that the highest percentage of the studied sample were maintaining environment hygiene (99.6\%), initiating a peripheral IV infusion $(74.4 \%)$ and discontinuing IV infusion (56.4\%). While less than half (43.6) were caring and maintaining the IV catheter.

Table (4): Showed that most of the studied internship nursing students had adequate practice (66.8\%) toward infection control precautions regarding IV infusion.

Table (5): Showed that there was statistically significant difference between internship nursing students' knowledge and their attending training programs about infection control precautions (P. $=0.017$ ).

Table (6): Demonstrated that there was nonsignificant correlation between internship nursing students' knowledge and their total practice about infection control precaution regarding IV infusion.

\section{Discussion}

Internship nursing students are viewed as a part of healthcare workers in clinical training placements. They are susceptible to healthcare-associated infections because of their direct patients' interactions during their clinical training. They might be the source of transmitting infection due to their limited knowledge and experience about infection control practices. So, compliance with infection control precautions is paramount during their clinical exposure and training (Cruz \& Bashtawi, 2016).

\section{I: Personal data of internship nursing students}

Regarding personal data, the present study showed that more than half of the studied samples were females, the majority of them were singles and their mean age was $23.3 \pm 1.5$. These findings supported by Goje et al., (2018) who found in their study about nursing students' knowledge and practice of standard precautions that most of students were females, singles and their mean age was $24 \pm 5$.

As regards attending training program about infection control precautions, the present study revealed that the majority of internship nursing students attended training program about infection control in orientation programs (preparation of internship nursing students before involving them in clinical training in hospitals) in period ranged between 1-3 days. This signifies the importance of orientation programs for nursing students.

The present study result was congruent with a study conducted by Al Yousef (2014) and entitled effect of nursing guidelines regarding infection control measures on performance of internship students, the study results showed that most of internship nursing students attended training program about infection control for one day. While the current study finding was in disagreement with the study about compliance with standard precautions during clinical training of nursing students in Saudi Arabia by Alshammari et al., (2018) who mentioned that the majority of the internship nursing students had not attended infection control training or seminar about infection control precautions.

II: Internship nursing students' knowledge about infection control precautions during IV Infusion

In relation to internship nursing students' knowledge toward infection control regarding IV infusion, this study clarified that all the internship nursing students were overall evaluated as having good level of knowledge. From researcher's point of view, this may be related to most of the students attended training courses in this field. Also, infection control unit taught to students within the nursing curriculum in their college. Furthermore outbreak of Coronavirus disease 2019 (Covid-19) had led to elevate the level of students' knowledge about infection control.

This study results supported by study entitled knowledge and information sources on standard precautions and infection control of health sciences students at King Saud bin Abdulaziz University for Health Sciences conducted by Khubrani et al., (2018) who clarified in their study about knowledge and information sources on infection control of Saudi-Arabian healthcare students that other than formal curriculum teaching, the elevated knowledge witnessed may be attributable to the outbreak of Middle East respiratory syndrome coronavirus (MERS-COV) in 2015. During this period students trained by infection control practitioners prior to or during their clinical years. Such interventions, theoretical knowledge, and practical learning may have increased students' knowledge of infection control.

Similarly the current study was consistent with Desta et al., (2018) \& Bai (2015) who concluded that most of the internship nursing students had good knowledge regarding infection control precautions. Also, Turan et al., (2018) in their study about nursing students' levels of knowledge on the prevention of intravascular catheter infections illustrated that nursing students had adequate knowledge on the prevention of IV catheter infections.

The present study was inconsistent with crosssectional study entitled Jordanian nursing students' knowledge of, attitudes towards, and compliance with infection control precautions done by Darawad \& Al-Hussami (2013) who reported that Jordanian nursing students had poor knowledge regarding infection control precautions. In line with 
D'Alessandro et al., (2014) who reported that the majority of internship nursing students had poor knowledge about infection control. They added that these findings might be due to the insufficient infection control training courses in the last academic semester of undergraduate nursing program.

Regarding the source of information about infection control precautions, the current study result revealed that the majority of internship nursing students' sources of their information about infection control were the studying and internet, while half of them were acquired their information from the organizational policies and procedures during practical training in the hospital, followed by infection control professional in organization, more senior nurse and scientific journals.

These findings were in line with the study done by Khubrani et al., (2018) who documented that the sources of information about infection control precautions were formal curricular teaching and informal practical learning in the ward. While, Mitchell et al., (2014) in their study about 'Australian graduating nurses' knowledge, intentions and beliefs on infection prevention and control, they found that the participants were most likely to seek infection control information from an infection control professional, followed by organizational policies and guidelines. They were significantly less likely to seek information from senior nurses, scientific journals or internet compared with consulting infection control professionals and hospital policies.

III: Internship nursing students' practice related to infection control precautions during IV infusion Regarding Internship nursing students' practice related to infection control precautions during IV infusion, the current study revealed that the highest percentage of the studied sample were maintaining environment hygiene, initiating a peripheral IV infusion and discontinuing IV infusion. While, less than half were caring and maintaining the IV catheter. This can be attributed to presence of well-designed clinical courses about infection control in undergraduate nursing program in addition to attending the orientation program before their involvement in clinical training in hospitals.

Similarly, Eskander et al., (2013) in their study about 'intensive care nurses' knowledge \& practices regarding infection control standard precautions at a selected Egyptian cancer hospital, documented that more than half of the studied sample had satisfactory performance level regarding infection control standard precautions for IV infusion therapy. However, the findings of present study were inconsistent with Al Yousef (2014) who found that internship nursing students had low level of performance regarding general measures of infection control standard precautions related to insertion of peripheral IV catheters and giving IV infusion.

Also, the results of present study agreed with crosssectional studies done by Ghazali \& Arbaee (2018) \& Osti et al., (2019) to determine the knowledge and practice towards caring and maintaining peripheral IV cannula among nurses, they revealed that majority of them followed the correct practice of care and maintenance of peripheral IV cannula. However, these results were in disagreement with Qamar et al., (2017) in their study about assess nurses knowledge and practices towards care and maintenance of peripheral intravenous cannulation, as they found that nurses' practices are lacking as regard caring and maintenance of IV catheter.

In relation to environment hygiene, the present study demonstrated that the majority of students maintaining a clean environment, these findings supported by study entitled 'awareness and practice of standard precaution for infection control among student nurses conducted by Jael et al., (2019) who reported that most of nursing students had good practice regarding infection control in terms of safe handling of needles and other sharp devices and maintaining safe environments. On other side, the current study was inconsistent with El-Sayed et al., (2015) who found that very low percentages from studied sample maintain a safe environment.

Generally, the present study clarified that about two third of internship nursing students had adequate practice toward infection control precautions regarding IV infusion. From researcher's point of view, this result may be due to outbreak the Covid-19 pandemic that made the nursing students had compliance with infection control precautions where, most internship nursing students attended training course in this field.

The study findings were in line with cross-sectional studies entitled assessment of the level of knowledge and practice on intravenous cannulization among staff nurses conducted by Hossain et al., (2016) \& Fashafsheh et al. (2015) as they found that majority of the respondents had adequate practice about infection control precautions.

However, the present study was in disagreement with Abdelaziz et al., (2019) in their study about infection prevention and control curriculum in undergraduate nursing program: Internship nursing students' perspectives' who mentioned that near half of internship nursing students had poor practice regarding infection control precautions. Also, Tawalbeh et al., (2019) in their study about the effect of infection control course on nursing students' knowledge of and compliance with universal precautions, indicated that nursing students were 
inadequately compliant with many infection control precautions. Explaining that the reason is the absence of well-designed clinical and theoretical courses about infection control.

Regarding relation between knowledge, practice and personal data of internship nursing students, the present study showed that there were statistically significant relations between training programs about infection control precautions and knowledge of internship nursing students. This results in agreement with Zeb et al., (2019) who found that a significant result was obtained between training of infection control and knowledge of responded about infection control precaution.

As regard the correlation between internship nursing students' knowledge and practice, the findings of present study revealed that, non-significant correlation was found between internship nursing students' knowledge and practice. From researcher's point of view, this could be due to the good level of knowledge and practice of internship nursing students about infection control regarding IV infusion. This study supported by study entitled knowledge and compliance of standard precautions among student nurses done by Labrague et al., (2012) who reported that there was no significant correlation between knowledge and compliance with standard precautions among nursing students. While, these results disagree with Abdelaziz et al., (2019) who found that significant correlation between the internship nursing students' knowledge and practice regarding the infection control precautions.

\section{Conclusion}

Based on the results of the present study, it can be concluded that:

Internship nursing students under study had good level of knowledge and adequate practice about infection control precautions regarding IV infusion.

\section{Recommendations}

- Based on the findings of present study, the following recommendations were derived:

- The periodic refreshing in-service training courses should be provided to internship nursing students in order to keep them with updating knowledge and practice regarding infection control precautions generally and regarding all nursing skills.

- Use of nursing guidelines as a routine care to prevent IV catheter-related infection.

- Written procedure manual regarding infections control precautions during IV infusion should be available in each ward as reference and should be up to date periodically to suite new trend of infection prevention.
- Healthcare organizations should improve training conditions for internship nursing students through availability of personal protective equipment (PPE), appropriate staff sizing and regular leadership support.

- Further studies on large sample from different geographic areas in Egypt to generalize the results.

\section{References}

- Abdelaziz, T., Dogham, R., \& Elcockanyn, N., (2019): Infection prevention and control curriculum in undergraduate nursing program, Internship nursing students' perspectives, Journal of Nursing Education and Practice, Vol.(9), No.(10), Pp. 59-65.

- Alshammari, F., Cruz, J., Alquwez, N., Almazan, J., Alsolami, F., Tork, H., Alabdulaziz, H., \& Felemban, E., (2018): Compliance with standard precautions during clinical training of nursing students in saudi arabia: A multi-university study, Journal of Infection in Developing Countries, Vol.(12), No.(11), Pp. 937-945.

- Al Yousef, S., (2014): Effect of Nursing Guidelines During Infection Control Measures on Performance of Internship Students in Applied Medical Science College at Hafr Al-Batin, IOSR Journal of Nursing and Health Science, Vol.(3), No.(4), Pp. 37-46.

- Anabtawi, R., Qtait, F., \& Hammad, B., (2019): Awareness of Nursing Students at AAUP towards Using Infection Control Strategies in Hospitals, Advanced Nursing \& Patient Care International Journal, Vol.(2), No.(1), Pp.1-6.

- Bai, H., (2015): Knowledge and Practice of Health Care Workers on Infection Control Measures. Asian Journal of Nursing Education and Research, Vol.(5), No.(4), Pp. 518.

- Blauw, M., Foxman, B., Rey, J., Kothari, N., and Malani, A., (2019): Risk Factors and Outcomes Associated with Hospital-Onset Peripheral Intravenous Catheter-Associated Staphylococcus aureus Bacteremia. Open Forum Infectious Diseases, Vol.(6), No.(4), Pp. 1-6.

- Beyamo, A., Dodicho, T., \& Facha, W., (2019): Compliance with standard precaution practices and associated factors among health care workers in Dawuro Zone, South West Ethiopia, cross sectional study. BMC Health Serv Res, Vol.(19), No.(381), Pp. 1-6.

- Centers for Disease Control and Prevention (CDC), (2017): Guidelines for the Prevention of Intravascular Catheter-Related Infections, online Accessed https://www.cdc.gov/infectioncontrol/guidelines/bsi /recommendations.html

- Cruz, J., \& Bashtawi, M., (2016): Predictors of hand hygiene practice among Saudi nursing 
students: A cross-sectional self-reported study, Journal of Infection and Public Health, Vol.(9), No.(4), Pp. 85-93.

- D’Alessandro, D., Agodi, A., \& Auxilia, F., (2014): Prevention of healthcare associated infections, Medical and nursing students' knowledge in Italy, Nurse Education Today, Vol.(34), No.(2), Pp. 191-195

- Darawad, M., \& Al-Hussami, M., (2013): Jordanian nursing students' knowledge of, attitudes towards, and compliance with infection control precautions, Nurse Education Today, Vol.(33), No.(6), Pp. 580-583.

- Desta, M., Ayenew, T., Sitotaw, N., Tegegne, N., Dires, M., \& Getie, M., (2018): Knowledge, practice and associated factors of infection prevention among healthcare workers in Debre Markos referral hospital, Northwest Ethiopia, BMC Health Services Research,BMC Health Services Research, Vol.(18), No.(1), Pp. 1-10.

- El-Sayed, Z., Gomaa, A., \& Abdel-Aziz, M., (2015): Nurses' Knowledge and Practice for Prevention of Infection in Burn Unit at a University Hospital, Suggested Nursing Guidelines, IOSR Journal of Nursing and Health Science Ver. I, Vol.(4), No.(4), Pp. 2320-1940.

- Eskander, G., Youssef, W., Morsy, M., Ali, H., \& Elfeky, A., (2013): Intensive Care Nurses' Knowledge \& Practices regarding Infection Control Standard Precautions at a Selected Egyptian Cancer Hospital, Vol.(4), No.(19), Pp. 160-174.

- Etafa, W., Wakuma, B., Tsegaye, R., \& Takele, T. (2020): Nursing students' knowledge on the management of peripheral venous catheters at Wollega University. PLoS ONE, Vol.(15), No.(9), Pp. 1-12.

- Fashafsheh, I., Ayed, A., Eqtait, F. and Harazneh, L., (2015): Knowledge and Practice of Nursing Staff towards Infection Control Measures in the Palestinian Hospitals, Vol.(6), No.(4), Pp. 79-91.

- Ghazali, M., \& Arbaee, I., (2018): Nurses Knowledge and Practice towards Care and Maintenance of Peripheral, Research Gate, Vol.(6), N0.(5), Pp. 1-39.

- Goje, M., Balami, D., \& Jarma, M., (2018): Knowledge, attitude, self-efficacy and practice of standard precaution measures by nursing and midwifery students in Damaturu, North-Eastern Nigeria, Vol.(1), No.(2), Pp. 41-46.

- Hossain, M., Arif, H., \& Haque, M., (2016): Assessment of the Level of Knowledge and Practice on Intravenous Cannulization among Staff Nurses of Selected Tertiary Care Hospital in Dhaka City, MOJ Public Health, Vol.(4), No.(5), Pp. 156-159.
- Jael, S., Maristela, E., Alano, R., Wushoma, T., \& Jumarang, L., (2019): Awareness and Practice of Standard Precautions for Infection Control among Student Nurses, Abstract Proceedings International Scholars Conference, Vol.(7), No.(1), Pp. 417-133.

- Khairunniza, G., Leela, C., \& Thiruselvi, S., (2019): Students' Perception of Their Knowledge about Peripheral Intravenous Cannulation at a Private Medical University in Seremban, Negeri Sembilan, Malaysia, Proceedings of ADVED 20195th International Conference on Advances in Education and Social Sciences, 21-23 October 2019- Istanbul, Turkey, ISBN: 978-605-82433-7-8, Pp. 649-662.

- Khubrani, A., Albesher, M., Alkahtani, A., Alamri, F., Alshamrani, M., \& Masuadi, E., (2018): Knowledge and information sources on standard precautions and infection control of health sciences students at King Saud bin Abdulaziz University for Health Sciences, Saudi Arabia, Riyadh, Journal of Infection and Public Health, King Saud Bin Abdulaziz University for Health Sciences, Vol.(11), No.(4), Pp. 546-549.

- Labrague, J., Rosales, R., \& Tizon, M., (2012): Knowledge and Compliance of Standard Precautions among Student Nurses in International Journal of Advanced Nursing Studies, Vol.(1), No.(2), Pp. 160-174.

- Mermel, L., (2017): New Research on IV Infection Risk in ICT Infection Control Today, Vol.(23), No.(6), Pp.32-64.

- Mitchell, G., Say, R., Wells, A., Wilson, F., Cloete, L., \& Matheson, L., (2014): Australian graduating nurses' knowledge, intentions and beliefs on infection prevention and control, A crosssectional study, BMC Nursing, Vol.(13), No.(1), Pp. 1-7.

- Osti, C., Khadka, M., Wosti, D., Gurung, G., \& Zhao, Q., (2019): Knowledge and practice towards care and maintenance of peripheral intravenous cannula among nurses in Chitwan Medical College Teaching Hospital Nepal, Nursing Open, Vol.(6), No.(3), Pp. 1006-1012.

- Qamar, Z., Afzal, M., Kousar, R., Waqas, A., \& Gilani, D., (2017): Assess Nurses Knowledge and Practices towards Care and Maintenance of Peripheral Intravenous Cannulation in Services Hospital Lahore Pakistan, Saudi Journal of Medical and Pharmaceutical Sciences, Vol.(3), No.(6), Pp. 608-614.

- Tawalbeh, L., Al-Rawajfah, M., \& Habiballah, L., (2019): The Effect of Infection Control Course on Nursing Students' Knowledge of and Compliance with Universal Precautions, A Quasi- 
experimental Study, Dimensions of Critical Care Nursing, Vol.(38), No.(3), Pp. 137-145.

- Turan, G., Mankan, T., \& Cengiz, Z., (2018): Nursing Students' Levels of Knowledge on the Prevention of Intravascular Catheter Infections, International Journal of Caring Sciences, Vol.(11), No.(2), Pp. 443-449.

- Zeb, A., Muhammad, D., \& Khan, A., (2019): Factors Affecting Nurses' Compliance to Standard Precautions in Resource Scarce Settings, American Journal of Biomedical Science \& Research, Vol.(4), No.(5), Pp. 384-389. 